\section{Queensland and Creationism}

SIR-In response to inaccurate statements made by Tony Thulborn (Nature 315, 89; 1985), I am writing to clarify my department's policy on the teaching of the theory of evolution in Queensland State secondary schools.

The Queensland Education Department policy on the teaching of the theory of evolution requires that it be taught (1) as a theory, not as fact; (2) in a balanced manner.

In providing balance, teachers must acknowledge that alternative theories to evolution exist. Some may be supported by scientific evidence; others may not be scientific in nature, but nevertheless based on beliefs deeply held by a significant proportion of the community.

Beyond this, I believe that the question of what constitutes "balance" should be left to the professional judgement of each and every science teacher. I hasten to add that I would be most concerned if a teacher taught the theory of evolution in such a way as to assail the religious beliefs of students. I would be equally concerned if the intent of a science syllabus, in terms of both "content" and "minimum time", were not adhered to.

Lin Powell (Minister for Education) Treasury Building,

Queen Street, Brisbane, 4000 , Australia

\section{Sexism and conservation}

SIR-The advertisement on the back cover of the 16 October issue of Nature shows a young woman clad in only a shell necklace. While past correspondence has discussed the issue of sexism in advertisements in your journal, we want to point out that many gastropods are fished and killed for the explicit purpose of making jewellery because local entrepreneurs have exhausted the dead shells that are washed up on beaches. In certain countries, especially those with tropical shorelines, this practice has reached epidemic proportions and constitutes a major threat to the resident molluscs ${ }^{1}$. Display of material that links (live) girls to (dead) prosobranchs can only damage efforts to conserve sea-shore fauna.

T. M. CARE

Sub-Department of Animal Behaviour,

University of Cambridge,

Madingley, Cambridge CB3 8AA, UK

Department of Applied Biology, W. K. LINDSAY

University of Cambridge,

Pembroke Street,

Cambridge CB2 3DX, UK

1. Kendall, B. Swara Magazine 8 (1), 8-11 (1986)

\section{Literary pedantry}

SIR-In "What is the scientific literature" (Nature 322, 681; 1986), John Maddox appears to be confusing the medium with the message. Although I, too, decry the poor writing that characterizes many scientific publications, this alone does not drum papers out of the ranks of 'literature'. On the contrary, any scientific paper meets all standard dictionary defini-

\section{Problems of Soviet refusniks}

SiR - We beg the courtesy of your columns to address a letter, signed by us and seven of our colleagues, to members of the World Federation of Scientific Workers (WFSW) and its president, Professor Jean-Marie Legay.

We had hoped to hand this letter personally to Professor Legay when he was in Moscow this summer for the General Assembly of WFSW. Indeed, when we telephoned him there he courteously agreed to meet the two of us at his hotel on the morning of $24 \mathrm{July}$, before the opening ceremony of the assembly. On arrival at the hotel, however, we were denied entry and had to telephone Professor Legay again to explain our difficulty, which he promised to try to deal with. Instead, after some delay, we were forced out of the hotel and away from the entrance area by a group of plain-clothes men who brutally ples. tions of 'literature', with the possible exception of the definition that is characterized as Archaic, namely, for example, "literary culture" (Dictionary of the English Language. Random House, New York, 1968). Maddox is barking up an antique tree.

Department of Biochemistry,

Melvin Blecher

Georgetown University,

Washington, DC 20007, USA

a group of plain-clothes men who brutally Moscow, USSR
To members of the world Federation of scientific workers

informed us that we had "no reason to meet Legay". Subsequent telephone conversations established Professor Legay's inability to arrange a meeting with us during the remainder of his stay in Moscow.

The text of the letter appears below.

We do not wish to embarrass Professor Legay and WFSW. Indeed, what happened on 24 July was as great a discourtesy to them, in being denied a visit by their invited guests, as it was an affront to us. Instead, what we wish to do is give WFSW, committed as it is to professional solidarity among scientists, the opportunity publicly to press for our professional rights and thus enhance its prestige as an organization dedicated to humane princi-

Alexander Ioffe BORIS KLOTZ

Dear Colleagues,

We believe that the WFSW, being an influential representative of the international scientific community, cannot ignore the plight of hundreds of scientists living in circumstances that leave them little chance to survive and preserve the ability to work in science.

We mean those who by one or another reason, national, religeous, professional declared the intention to leave the USSR for Israel but was not granted the possibility to do so. Many continue their efforts for 10,15 and even more years being practically deprived of any kind of scientific communication and, very often, of any real possibility to continue their professional activity. professional activity. Many lost their jobs, fur about their future and the future of their families.

Meanwhile, we believe that the problem we are talking about is not among the most difficult-to-solve problems dividing the world. We believe that a just solution to the problem can easily be found if there is goodwill and understanding. We finally believe that, being found, such a solution would substantially contribute to the atmosphere of trust and cooperation between countries and societies.

The world scientific communuty has many times proved its determination and ability to defend human dignity and professional rights of scientists. We know of many activities undertaken by various scientific organizations and know of many activities uniertalen Jewish emigration in general or certain individuals whose circumstances were especiall difficult. We call Wrsw to join these efforts: the future of the world is unseparable from the futue of individual human beings. Such a constructive demonstration of goodwill and professional solidarity would completely correspond to the humane principles proclaimed by the Federation.

Victor Fulmacht Alexander Ioffe Mikhail Kholmyansky Boris Klotz Yuli Kosharovsky Erlena Matlina Vladislav Tladislav Ryaboy Yosif Zaretzky

Moscow, 24 July, 1986 